\title{
Dynamic Changes in Maritime Research Capability in Chinese Universities
}

\author{
Young-Tae Chang, ${ }^{1}$ Ahhyun Jo, ${ }^{1}$ and Kyoung-Suk Choi $\mathbb{D}^{2}$ \\ ${ }^{1}$ Graduate School of Logistics, Inha University, Incheon, Republic of Korea \\ ${ }^{2}$ Department of International Trade, Chonbuk National University, Jeonju, Republic of Korea
}

Correspondence should be addressed to Kyoung-Suk Choi; koyaku@jbnu.ac.kr

Received 22 February 2019; Revised 22 June 2019; Accepted 17 July 2019; Published 25 August 2019

Academic Editor: Shamsunnahar Yasmin

Copyright (C) 2019 Young-Tae Chang et al. This is an open access article distributed under the Creative Commons Attribution License, which permits unrestricted use, distribution, and reproduction in any medium, provided the original work is properly cited.

\begin{abstract}
This study determines the top fifty authors in China and their university affiliations in the maritime transportation field, compared to their world ranking. We refer to China in the broad sense of the Chinese economies, including not only mainland China and Hong Kong, but also Chinese Taipei (Taiwan) and Singapore. This study analyzes sixty-five SSCI and SCI journals in the field of maritime and transportation between the years 2000 and 2015. In terms of ranking, three indicators are employed: total number of articles, weighted score (indication of author contribution), and the impact score. With the exception of Shanghai Jiao Tong University, no other universities selected in the first phase of Project 985, which received billions of dollars in government support/aid, were listed in the world ranking. Star authors are deemed to have contributed greatly to the rankings of their affiliated universities. The future of China's rankings is bright in view of the increasing number of papers being published by Chinese authors and universities and their strong grounding in quantitative methodologies.
\end{abstract}

\section{Introduction}

The Chinese economy today is second only to that of the USA, due to its open door policy. Even as China was being driven by the open-door policy and enjoying unprecedented economic growth, China's leaders began to recognize the importance of education to further boost economic growth and social development. In February 1993, the Chinese authorities launched the "Program for Education Reform and Development in China," in order for the central and local governments to focus on 100 key universities. In May 1995, the Communist Party of China (CCP) and the State Council, the cabinet of China, jointly issued the Decision to Speed up the Advancement of Science and Technology, with the State Council launching "Project 211" in 1995. Motivated by the development of China's higher education under Project 211, then President Jiang Zemin asserted in May 1998 that China must have several first-rate universities of an advanced international level. In December 1998, the "Action Plan to Vitalize Education in the 21st Century" was promulgated by the Ministry of Education for concentrating limited resources to develop world-class universities within 20 years. President Jiang's policy was named "Project 985." Peking and Tsinghua universities were the first recipients, receiving 1.8 billion yuan (US\$225 million) in the first round of special funding for three years from 1999. From July to November 1999, another seven universities were added to Project 985 . By 2006, a total of 37 universities had been brought under the project scope. The universities were awarded special funds of billions of yuan each by both the central government and the respective local governments [1].

Against this backdrop, it is an intriguing research question whether China's quest for world class universities has been satisfied in the maritime transportation area. More specifically, it seems to be timely, in view of the two decade-long government policy of developing world class universities, to single out the most productive researchers and institutions in China for maritime research, and to investigate whether their contributions are equivalently recognized in the literature. Logistics and supply chain literature 
has determined author and school rankings [2-5], having updated them four times between 1981 and 2005. Although Carter et al. [4] identified top universities and journals in transportation/logistics, there has been no research analyzing maritime transportation. Some review papers, including Woo et al. [6], have focused on methodological or topical trends in maritime study, including seaport research. Woo et al. [7] again inspected 840 seaport research papers during the 1980s2000s to observe how general research trends had changed and identify research sub-themes. They also investigated collaboration trends among researchers, identifying singleand multiple-author papers. More recently, Lee et al. [8] and Davarzani et al. [9] dealt with sustainable maritime issues. Lee et al. [8] examined the methodological trend by analyzing nearly 1,300 papers in 51 transportation and environment journals, while Davarzani et al. [9] examined maritime studies on green issues. Chang et al. [10] examined the top 50 researchers, schools, and countries in the world for maritime research. To the authors' knowledge, despite these studies, no studies have yet conducted detailed analysis on author and school performance in Chinese maritime research.

Therefore, this study can contribute to the literature and benefit the readers of this journal in the following ways. The results of this study are expected to serve as an important guideline for students in choosing graduate programs and professors in the field of maritime transport. Furthermore, the number of papers published in the SSCI and SCI journals in China recently has become important as an indicator of university competitiveness, which in turn becomes a source of attracting leading scholars and motivation for schools. Finally, the result of this research can be used to evaluate whether the investment of government or school on education are effective.

To this end, this paper examines the top 50 authors affiliated with Chinese research institutions (mostly universities) in the field of maritime transportation in comparison with their world rankings. In addition, it investigates what factors influence research performance. China in this paper refers, in the broad sense, to the Chinese economies including not only mainland China and Hong Kong, but also Chinese Taipei (Taiwan) and Singapore, as there is close collaboration and trade relationships in these economies, both in industry and academia. The analysis covers articles published in 65 Social Sciences Citation Index (SSCI) and Sciences Citation Index (SCI) maritime and transportation journals over sixteen years (from 2000 to 2015). For the purpose of ranking, this study employs three indicators: the number of papers, the weighted score (indicating author contribution), and the impact score that reflect the impact factor.

Section 2 explains the methodology of selecting relevant journals and papers, and various methods of rating the authors and institutions. Section 3 describes and discusses the results and implications, prior to concluding in Section 4.

\section{Methodology}

This paper's methodology builds on the work of Chang et al. [10]. This section gives minimal description; for further details, readers should refer to Chang et al.s [10] paper.

First, we selected key journals by building upon Lee et al. [8] work, in which they confined their selection to those journals registered with SCI, SCI (E) and SSCI, covering 59 major transportation journals. Second, we added some Operations Research (OR) journals, following Woo et al. [7], and the initial list of 59 journals was expanded to 69 journals. Third, to check if any important journals were missing, further validation was carried out by selecting the most active maritime researchers (see Chang et al. [10] for the full names of the selected researchers) and comparing their publication records against the selected 69 journals. We added missing journals from the publication lists of the active researchers, and the number increased to 85 . Fourth, among the 85 journals, we excluded those whose scope did not adequately cover maritime studies as well as those journals on which the Web of Science and Scopus do not have necessary information for the analysis, resulting in a final sample of 65 journals (see Chang et al. [10] for the full list).

From our search for the relevant key words, we discovered that "shipping" was the most researched field in maritime transport; more specifically, topics related to port, including "port management, service, performance, efficiency and competitiveness," were the most popular, as well as "shipping market, industry, freight rate and economic impact"; and "terminal studies" [11]. Furthermore, research on seaport has grown steadily since the 1980 s to become a dominant theme in maritime research [7]. In the field of maritime engineering and technology, the topics included "ship traffic", ship design, ship dynamic and hydrodynamics, onboard system, and ship structures, risk, and reliability [12]. Through this extensive search effort in the literature, we were able to select 9 key words in maritime research.

In terms of keyword search, we initially worked with following nine: "port," "shipping," "maritime," "marine," "terminal," "ship," "liner," "vessel," and "seaport." We then expanded and adjusted these keywords following Davarzani et al. [9] and examined whether the keyword search was missing any papers of key researchers. The following 13 keywords were found to be sufficient for our purpose: "port," "shipping," "maritime," "marine," "terminal," "ship," "liner," "vessel," "seaport," "water transportation," "ocean freight," "container," and "waterway transport." When we surveyed the articles in the maritime field using the keywords, we deleted words like "highway", "intersection", "helmet", "pedestrian", "fish", "guardrail", "aviation", and "fishery" which might be confused with other research fields.

We relied on three criteria: the number of papers published, weighted score, and impact score. In case of the $\mathrm{H}$ index which is widely used index measuring both the productivity and citation impact of the publications of authors for academic impacts, it only shows the most cited number of papers versus citations, while the impact score also contains information about the contribution of the first author or the corresponding author. Also, the $\mathrm{H}$ index loses information 
because it expresses the number of citations and papers as a minimum. For example, if a person wrote a single article and it was published in a prestigious journal with very high impact factor, the $\mathrm{h}$ index is only 1 . Therefore, we excluded the $\mathrm{H}$ index. Given that the $\mathrm{H}$ index is widely used in the academia, the comparison between the $\mathrm{H}$ index and other criteria would be an interesting research topic in the future. In this study, we only focus on three criteria for the aforementioned reasons.

Many existing studies have used the first criterion to measure author performance [4, 9]; however, this evades the challenge of multiple authors. In order to appropriately account for author contribution, particularly those of the first and corresponding authors, we adopted a measure that provides a weighted score for each author as follows.

$$
\text { Weighted Score for } j=\frac{1+\max \left(0, I_{j}^{f}, I_{j}^{c}\right)}{N_{j}+\max \left(0, I_{j}^{f}, I_{j}^{c}\right)}
$$

where $j$ indicates a specific paper. $N_{j}$ is the total number of authors of paper $j$. If an author is the first author of paper $j$, $I_{j}^{f}$ takes the value of 1 , and 0 otherwise. Similarly, if an author is the corresponding author of paper $j, I_{j}^{c}$ is 1 , and 0 otherwise.

Since papers published in prestigious journals tend to have greater "impact," it is necessary to adjust the score to account for the "impact factor." We calculate this statistic by dividing the total number of citations over the past two years by the total number of papers published during the same period in a journal. The impact factor is generally agreed to be a reliable and reasonable measure of journal quality $[13,14]$. The Journal Citation Reports published by Thompson Reuters makes this statistic available. Some journals only had a few impact scores for some years because of their relatively recent acceptance by SCI (E) or SSCI; for example, Maritime Policy \& Management in 2011. In such cases, the impact factor in the entry year was used for the prior periods (e.g., for the period 2000-2010, we considered the impact factor of Maritime Policy \& Management to be the same as its impact factor in 2011).

We calculated the impact score as follows:

$$
\begin{aligned}
& \text { Impact Score of } j \\
& =\text { Weighted Score of } j \\
& \quad \times \text { Impact Factor of the jounal that accepted } j
\end{aligned}
$$

To investigate what factors influence research works, ANOVA was untaken with the impact score as the dependent variable. For the independent variables, we considered the following: (1) the ratio of multi-authored papers; (2) the average number of authors per paper; (3) school rankings from the author's latest affiliation; (4) a dummy variable for country; and (5) a dummy variable for the authors' major. Analysis of the data shows that the ratio of multi-author papers has increased sharply in contrast with decreasing single-author papers. Additionally, the number of authors was considered. Following Gorman and Kanet $[15,16]$, who introduced the author affiliation index (AAI) to evaluate the quality of operations management journals in terms of impact factor, we used the school rankings of the authors. Moreover, the authors' major for their doctoral degree, which can represent their primary expertise, was included. Finally, we took the country dummy variable into account to identify national differences, which the above-mentioned variables cannot explain. When assigning country and major dummy variables, the country dummy variable was based on China, and the major was given a dummy value based on economics.

Since the data set seemed to have an extreme value, the Bonferroni outlier test was conducted. All information came from web journal data bases except for school rankings, which came from QS World University Rankings (https://www.topuniversities.com) or ARWU World University (http://www.shanghairanking.com) or UniRank (https://www.4icu.org).

\section{Results}

3.1. Scoring Result. The number of papers published in China with maritime research themes have increased rapidly from 17 and 10 papers in 2000 and 2001, respectively, to 147 papers in 2015 amounting to an almost fifteenfold increase. The number of papers has almost doubled every five years, and the range of journals has also widened from 25 journals for the 2000-2005 period to 64 journals for the 2011-2015 period. Most of the papers were multi-authored, while singleauthored papers have gradually declined from $20 \%$ in the early period to $10 \%$ lately.

Table 1 lists the top fifty authors by the three metric methods. The meaning of "top researcher" is directly related to the results of the analysis that rank the top 50 researchers. In addition, in this paper, author's country is based on the nationality of affiliation which they belong to when the paper was published. Therefore, if a Chinese researcher published a paper in other country except the four economies, that research is not counted in this analysis. Meng Qiang from the National University of Singapore (NUS) is the top researcher in all three methods. He published 52 papers during 16 years averaging 3.25 papers per year. His score by authornumber weighting method is 22 , implying that he mostly published his papers with at least two or three co-authors. His impact score is 39.6 indicating that he published his papers mainly in top tier journals in terms of impact factor. The next high-ranked authors in terms of the number of papers are T.C.E. Cheng, from the Hong Kong Polytechnic University (HKPU), and Jasmine Lam, from the Nanyang Technological University (NTU) in Singapore, both of whom published 32 papers over the period, averaging two papers per year. In author-weighted score, Lam scores 16.3 and Cheng 8.2, indicating that Lam must have coauthored with one other researcher and Cheng with three other researchers on average. In both author-weight and impact scores, Lam remains as the number two researcher, whereas Cheng drops significantly to seventh and eighth places, respectively. The following researchers in the top 10 researcher tier are from and/or currently affiliated with HKPU, namely Venus Lun, Chin-Shan Lu, Kee-hung Lai, Andrew Lim, Meifeng Luo, and Tsz Leung Yip. The exceptions are Paul Tae-Woo Lee (Kainan 
TABLE 1: Ranking by author.

\begin{tabular}{|c|c|c|c|c|c|c|}
\hline Rank & Author & No. of papers & Author & Weighted score & Author & Impact score \\
\hline 1 & Meng, Qiang & 52 & Meng, Qiang & 22.0 & Meng, Qiang & 39.6 \\
\hline 2 & Cheng, T. C. E. & 32 & Lam, Jasmine Siu Lee & 16.3 & Lam, Jasmine Siu Lee & 22.4 \\
\hline 3 & Lam, Jasmine Siu Lee & 32 & Lu, Chin-Shan & 13.4 & Lu, Chin-Shan & 14.4 \\
\hline 4 & Lun, Y. H. Venus & 26 & Lun, Y. H. Venus & 10.0 & Lun, Y. H. Venus & 13.3 \\
\hline 5 & Lu, Chin-Shan & 25 & Luo, Meifeng & 9.2 & Luo, Meifeng & 13.0 \\
\hline 6 & Lai, Kee-hung & 25 & Lee, Paul Tae-Woo & 9.0 & Lim, Andrew & 12.3 \\
\hline 7 & Lim, Andrew & 25 & Cheng, T. C. E. & 8.2 & Lee, Paul Tae-Woo & 12.1 \\
\hline 8 & Lee, Paul Tae-Woo & 25 & Lee, Der-Horng & 7.9 & Cheng, T. C. E. & 10.7 \\
\hline 9 & Luo, Meifeng & 20 & Yip, Tsz Leung & 7.4 & Lee, Der-Horng & 10.5 \\
\hline 10 & Lee, Der-Horng & 18 & Lim, Andrew & 7.1 & Yip, Tsz Leung & 10.2 \\
\hline 11 & Yip, Tsz Leung & 16 & Lai, Kee-hung & 6.6 & Lee, Chung-Yee & 9.8 \\
\hline 12 & Wong, Christina W. Y. & 14 & Thai, Vinh V. & 6.2 & Lai, Kee-hung & 9.2 \\
\hline 13 & Yang, Zhongzhen & 11 & Yang, Yi-Chih & 6.0 & Zhu, Wenbin & 8.9 \\
\hline 14 & Lee, Loo Hay & 11 & Yang, Ching-Chiao & 4.3 & Zhen, Lu & 7.0 \\
\hline 15 & Zhu, Wenbin & 11 & Zhu, Wenbin & 4.0 & Yang, Yi-Chih & 6.4 \\
\hline 16 & Fu, Xiaowen & 10 & Lee, Chung-Yee & 3.9 & Thai, Vinh V. & 6.1 \\
\hline 17 & Thai, Vinh V. & 10 & Wong, Christina W. Y. & 3.7 & Lee, Loo Hay & 5.5 \\
\hline 18 & Lee, Chung-Yee & 10 & Chao, Shih-Liang & 3.7 & Chao, Shih-Liang & 5.2 \\
\hline 19 & Liu, Liming & 10 & Yang, Zhongzhen & 3.5 & Yang, Ching-Chiao & 5.1 \\
\hline 20 & $\mathrm{Xu}$, Zhou & 8 & Wang, Dong-Hua & 3.5 & Wong, Christina W. Y. & 5.1 \\
\hline 21 & Cao, Jin Xin & 8 & $\mathrm{Xu}, \mathrm{Zhou}$ & 3.3 & Wang, Dong-Hua & 5.0 \\
\hline 22 & Yang, Yi-Chih & 7 & Ho, Joshua & 3.0 & Ho, Joshua & 4.8 \\
\hline 23 & Yang, Ching-Chiao & 7 & Chen, Lu & 3.0 & Zheng, Jianfeng & 4.8 \\
\hline 24 & Chen, Gang & 7 & Zhen, Lu & 3.0 & Lin, Dung-Ying & 4.7 \\
\hline 25 & Wang, Tingsong & 7 & Lee, Loo Hay & 2.9 & Wu, Wei-Ming & 4.4 \\
\hline 26 & Fan, Lixian & 7 & Liu, Liming & 2.7 & Shiau, Tzay-An & 4.3 \\
\hline 27 & Qu, Xiaobo & 6 & Hsu, Wen-Kai K. & 2.7 & Zhu, Ling & 3.9 \\
\hline 28 & Jin, Jian Gang & 6 & Zhang, Abraham & 2.7 & Lee, Yusin & 3.8 \\
\hline 29 & Shang, Kuo-Chung & 6 & Chen, Gang & 2.6 & $\mathrm{Fu}$, Xiaowen & 3.7 \\
\hline 30 & Chao, Shih-Liang & 6 & Wu, Wei-Ming & 2.5 & Chen, Lu & 3.7 \\
\hline 31 & Feng, Cheng-Min & 5 & Wang, Tingsong & 2.4 & Chen, Gang & 3.7 \\
\hline 32 & Huang, Dao-Zheng & 5 & Shiau, Tzay-An & 2.3 & Liu, Liming & 3.7 \\
\hline 33 & Li, Yi-Zhou & 5 & Shang, Kuo-Chung & 2.3 & Yang, Zhongzhen & 3.5 \\
\hline 34 & Tseng, Po-Hsing & 5 & Feng, Cheng-Min & 2.3 & Wu, Yen-Chun Jim & 3.4 \\
\hline 35 & Du, Yuquan & 5 & Chen, Shun & 2.3 & Tang, Loon Ching & 3.4 \\
\hline 36 & Wang, Hua & 5 & Sheu, Jiuh-Biing & 2.3 & $\mathrm{Xu}$, Zhou & 3.4 \\
\hline 37 & Chen, Lu & 5 & Fu, Xiaowen & 2.2 & Wei, Lijun & 3.3 \\
\hline 38 & Chen, Shun & 5 & Fan, Lixian & 2.2 & Hsu, Wen-Kai K. & 3.0 \\
\hline 39 & Liu, Xin & 5 & Lin, Dung-Ying & 2.2 & Wang, Hua & 3.0 \\
\hline 40 & Yang, Dong & 4 & Tseng, Po-Hsing & 2.2 & Cao, Jin Xin & 3.0 \\
\hline 41 & Wang, Xinchang & 4 & Chu, Hsing-Chung & 2.0 & Weng, Jinxian & 3.0 \\
\hline 42 & Zheng, Jianfeng & 4 & Wan, Yulai & 2.0 & Zhang, Abraham & 3.0 \\
\hline 43 & Hsu, Wen-Kai K. & 4 & Song, YH & 2.0 & Wang, Tingsong & 2.9 \\
\hline 44 & Weng, Jinxian & 4 & Jin, Jian Gang & 2.0 & Jin, Bo & 2.9 \\
\hline 45 & Cao, Zhi & 4 & Zeng, Qingcheng & 2.0 & Jin, Jian Gang & 2.9 \\
\hline 46 & Zhang, Abraham & 4 & Zheng, Jianfeng & 1.9 & Shang, Kuo-Chung & 2.9 \\
\hline 47 & Lee, Tsung-Chen & 4 & Laih, Chen-Hsiu & 1.8 & Ku, Kuo-Cheng & 2.8 \\
\hline 48 & Wang, Dong-Hua & 4 & Jane, Chin-Chia & 1.8 & Jane, Chin-Chia & 2.8 \\
\hline 49 & Li, Wenkai & 4 & Weng, Jinxian & 1.8 & Liu, Xin & 2.8 \\
\hline 50 & Wei, Lijun & 4 & Lee, Tsung-Chen & 1.8 & Yang, Chih-Te & 2.8 \\
\hline
\end{tabular}


University, Chinese Taipei) and Der-Horng Lee (NUS). It is noteworthy that Paul Tae-Woo Lee, who is currently affiliated with Zhejiang University, stands as the top-ranked maritime researcher among those working in mainland China.

Looking into the dynamic change of author rankings by impact score method every five years (Table 2), the deviation columns show changes in ranking from the previous period. If they newly appeared for that period, changes are not reported. In the field of maritime, changes in ranking are easily noticeable. For instance, many of the top 50 authors during the period of 2000-2005 fail to appear in the next period, which means that nearly all top 50 authors in the 2006-2010 period are new additions. A similar pattern is observed for the periods of 2006-2010 and 2011-2015. The top four researchers among the top five in 2006-2010, namely Ho, Lee, Lun and Thai were new entrants. Again, all top five researchers in 2011-2015-Meng, Lam, Luo, Lee (Paul TW) and Lee (CY)-reshuffled the top positions. Some researchers made remarkable jumps in their rankings. Chin-Chia Jane, Andrew Lim, TCE Cheng, and Jasmine Lam improved their rankings by $49,60,46$, and 48 places, respectively in the second period of 2006-2010. Meifeng Luo, Paul Lee, Wenbin Zhu, and Loo Hay Lee also improved their rankings enormously in the latest period by $81,51,128$, and 99 places, respectively. On the other hand, some researchers gradually disappeared from the rankings. Chin-Shan Lu topped the first and second period in the ranking, but dropped significantly in the latest period to $17^{\text {th }}$ position. Similarly, Der-Horng Lee, once third researcher in the second period dropped to $13^{\text {th }}$ in the latest period. Combining Tables 1 and 2, researchers could join the top ten tier by publishing their papers mostly in a single period of five years. Qiang Meng became the top researcher by publishing most of his papers in the period of 2011-2015, during which he also acquired 37.2 impact scores out of the 39.6 scores that he gained in total. Similarly, Paul TW Lee scored 10.4 in this period out of his total 12.1 points.

Next, rankings by affiliation are listed in Table 3. HKPU and NUS compete with each other to be the top research institution. HKPU surpasses NUS in terms of the number of papers by 19 papers and that of author-weight scores by 12.4, but falls behind NUS in impact score by 10.6 points. The next competitive group are the National Taiwan Ocean University (NTOU), Shanghai Jiao Tong University (SJTU), and Nanyang Technological University (NTU). NTOU performs better than the other two in both the number of papers and author-weight scores, but NTU surpasses the others in impact scores. It is interesting to see which universities stand in the top 10 tier group. Overall, four institutions from Hong Kong join this tier, namely HKPU, Hong Kong University of Science and Technology, City University of Hong Kong, and the University of Hong Kong. Two universities join the league from each of the remaining economies: NUS and NTU from Singapore; NTOU and National Cheng Kung University from Chinese Taipei; and SJTU and Dalian Maritime University (DMU) from mainland China. In the next top 20 group, several universities from mainland China show up, such as Beijing Jiaotong University (BJU), Chinese Academy of Science, Shanghai Maritime University, Shanghai University, and Huazhong University of Science and Technology.

3.2. ANOVA Result. Stepwise regression analysis reported that only the dummy variables for country and major were statistically significant among the initially considered variables. Although the field of economics, engineering, management, and OR are not representative of all social sciences, they are presumably classified as the most representative and comprehensive majors in this research. Because country and major variables are all dummy variables, we used the twoway ANOVA to estimate the effect of explanatory variables on the impact score. The ANOVA is a statistical method to identify whether there are significant differences among sample groups. Before conducting two-way ANOVA on the data set, the Bonferroni test was conducted to identify extraordinary observations (researcher) that can affect the significance of the model. In Table 4, the Bonferroni p-value for an observation having the biggest residual shows that the observation is a significant outlier representing less than 0.001 $p$-value. The two residual plots of Figure 1 also show the strong evidence for the outlier (1).

Based on the Figure 1 and Bonferroni test, we eliminated a single outlier (Meng, Qiang) and conducted the ANOVA test. Table 4 shows that country, major, and interaction term of the two have statistically significant effect on the impact score. To investigate the detail of variable' impacts, we draw box plots for two variables. Figure 2 displays two box plots according to categories: major and country. Both box plots show the outlier (Meng, Qiang) again in the engineering and Singapore category, which is same as residual plots. The width of boxes represents a relative frequency of observations. The left graph shows that engineering and management are the most popular major among the Chinese maritime researchers. However, their achievements in terms of impact score are opposite to the popularity showing the distribution of low scores and median value (horizontal line in the box). On the other hand, although the number of researchers who majored economics were small, they had a distribution of relatively higher impact scores. Management major shows the distribution of the lowest impact scores except the two outliers. The interesting point is that although researcher who majored engineering and management are majority of Chinese maritime academia, minority of researcher who majored economics, OR, and science achieved a higher impact score on average

The right side of Figure 2 shows the national difference of impact score. The width of boxes shows that China, Hong Kong, Singapore and Taiwan have a similar number of maritime researchers. The top two countries having a distribution of high scores are Hong Kong and Singapore. It implies that two countries' maritime researcher published papers in prestigious journals in general. The difference is that Singapore has two outstanding researchers. This result corresponds with the result of Man, J. P. et al. [17] who found that the English proficiency of a country has a positive impact on the national publication output. This result also matches with the national TOEFL ranking announced by Educational Testing Service [18]. However, these interpretations have 

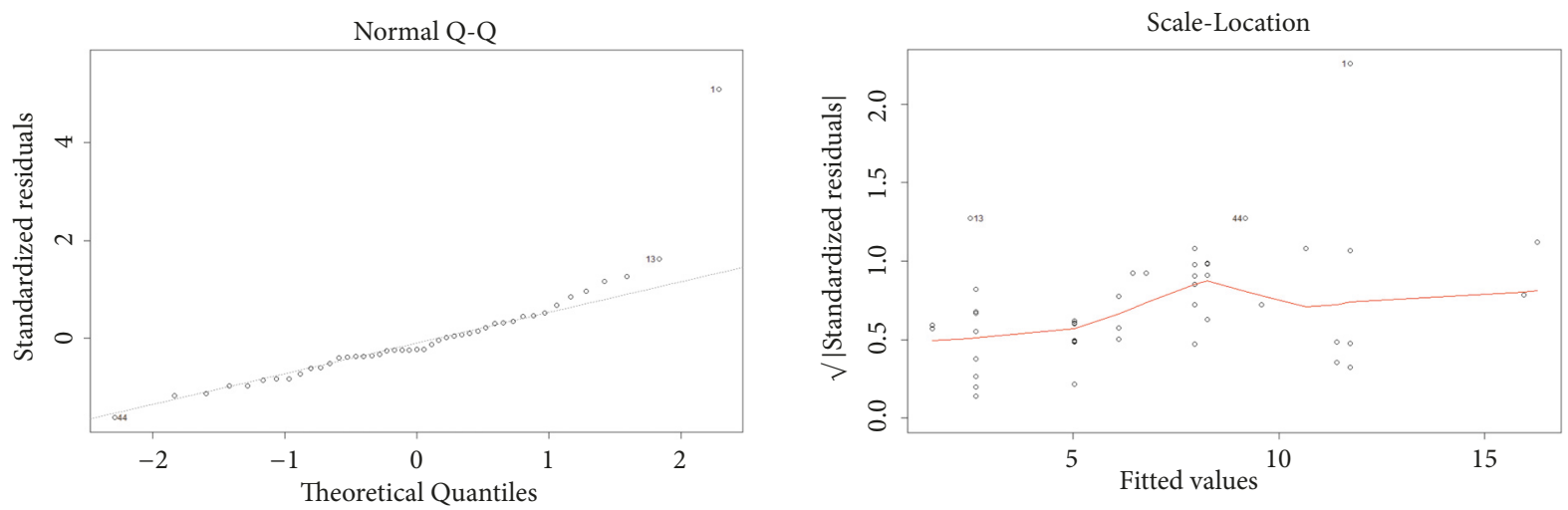

FIgure 1: Residual Plots.
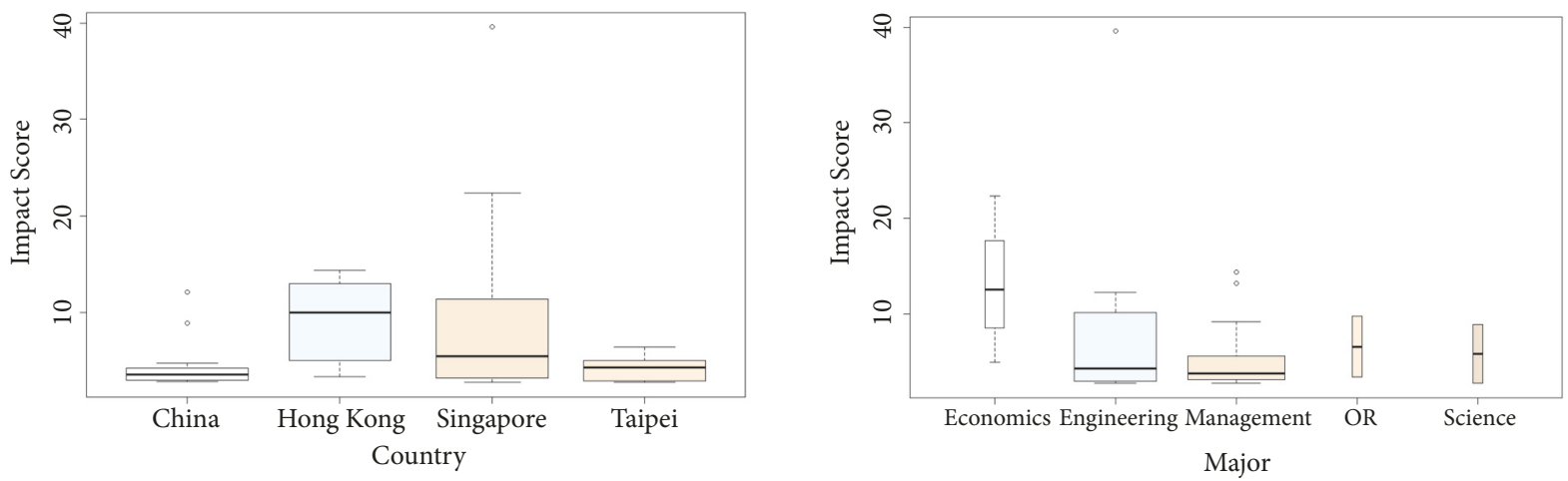

FIGURE 2: Impact score by country and major in boxplot.

some limitations because this analysis is only based on top 50 researchers. For example, Chang et al [10] found that China is the third country based on impact score recording 586 score. On the other hand, the rankings of Taiwan, Singapore and Hongkong are $8^{\text {th }}, 11^{\text {th }}$, and $31^{\text {st }}$. This implies that while China is very academic as a whole country, Singapore and Hongkong have a few number of very prominent scholars.

3.3. Implication of Result. The Chinese government has long envisioned raising the standard of key universities to eminent world status. To this end, they formulated two policies: Project 211 in 1993 to build 100 key universities and Project 985 in 1998 to develop world class universities in 20 years. Almost two decades have passed since the implementation of the policies and billions of dollars have been invested. Our research team earlier conducted a study on the top 50 authors, schools, and countries in maritime research. The world's top two universities in the maritime research arena are HKPU and NUS, which have competed with each other to be the top school. Reviewing universities in the mainland, four are listed in the world rankings: SJTU, DMU, BJU, and Shanghai University. Of these, SJTU leads, ranking $12^{\text {th }}$ in the number of papers, $13^{\text {th }}$ in author-weight score, and $21^{\text {st }}$ in impact score. DMU follows, ranking $19^{\text {th }}, 21^{\text {st }}$, and $24^{\text {th }}$ across the same parameters. BJU and Shanghai University show up only in the impact score ranking a $45^{\text {th }}$ and $48^{\text {th }}$ positions, respectively. Though SJTU and DMU are listed near the top 20 category, their rankings by impact factor score have caused them to drop to the top 30 tier. What is worse is that SJTU is the only university of the original nine selected for Project 985 that is listed in the world ranking. The remaining eight universities, namely Peking, and Tsinghua universities, University of Science and Technology of China, Fudan University, Nanjing University, Xi'an Jiaotong University, Zhejiang University, and Harbin Institute of Technology, do not seem to have channeled their efforts into conducting maritime research. Examining their presence within China (Table 3), it is fairly clear that only three institutions out of eight are listed and then, only in the bottom two tiers. Zhejiang University was $43^{\text {rd }}, 32^{\text {nd }}$, and $37^{\text {th }}$ in the number of papers, author-weight scores and impact scores; Nanjing University was $37^{\text {th }}$, over $50^{\text {th }}$, and $32^{\text {nd }}$; and the University of Science and Technology of China was $45^{\text {th }}$, $40^{\text {th }}$, and $43^{\text {rd }}$, respectively.

In order to get a better perspective on the low world rankings of mainland China's affiliations in maritime research, their contributions to journals and their share in the world total based on impact scores were calculated. The number of maritime research papers in the world increased ninefold between 2000 and 2015 and the counterpart papers published in China increased fifteenfold. As shown in Figure 3, the share of Chinese economies papers in the world total has increased from $13.1 \%$ in the $2000-2005$ period, to $16.5 \%$ in $2011-$ 2015. Moreover, mainland China's proportion of papers has 


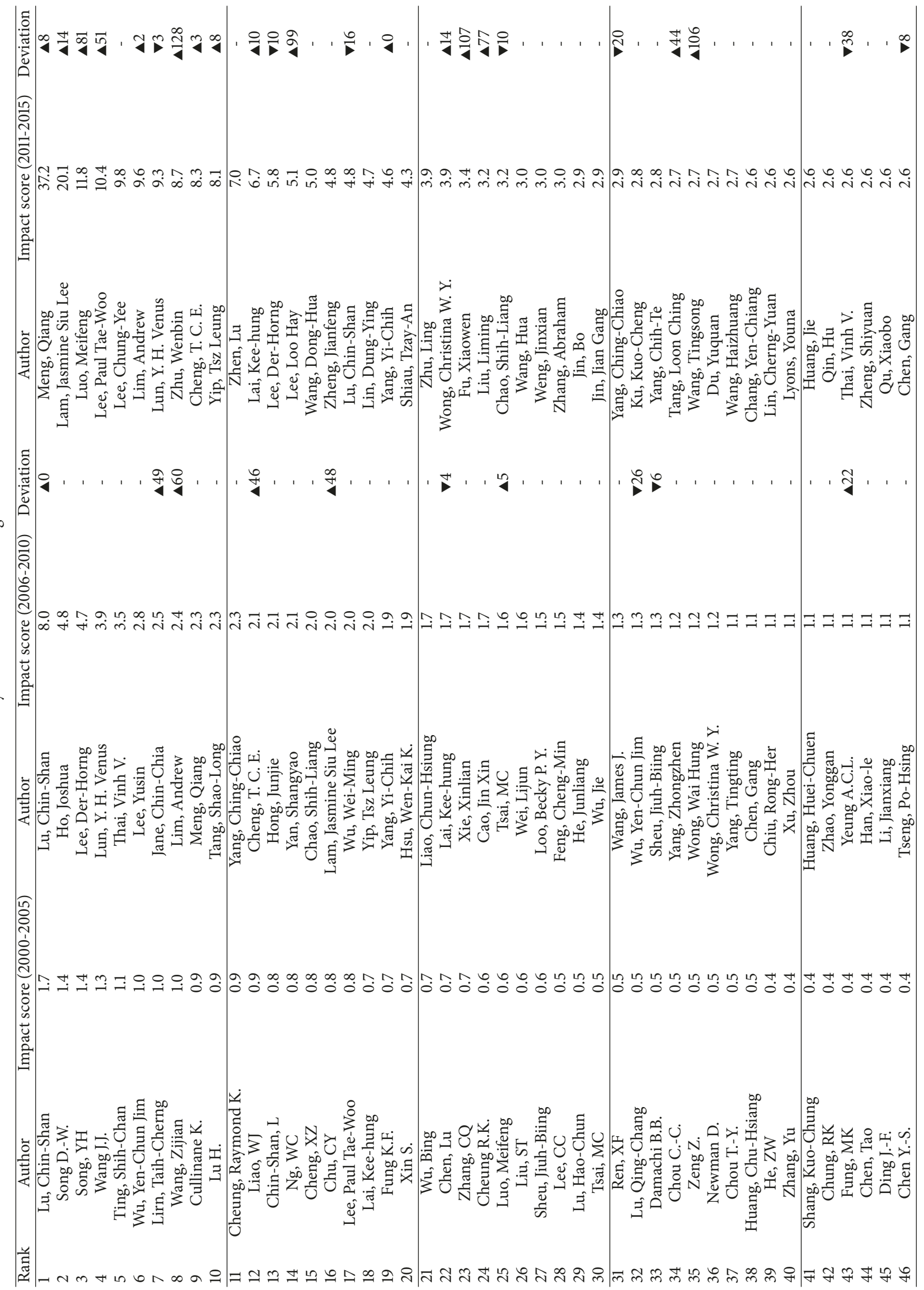




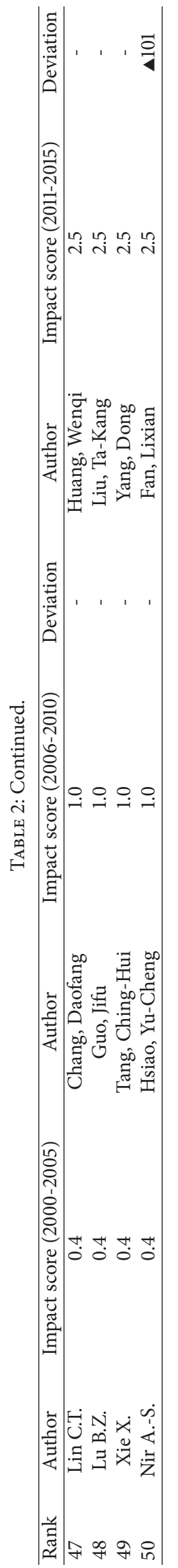




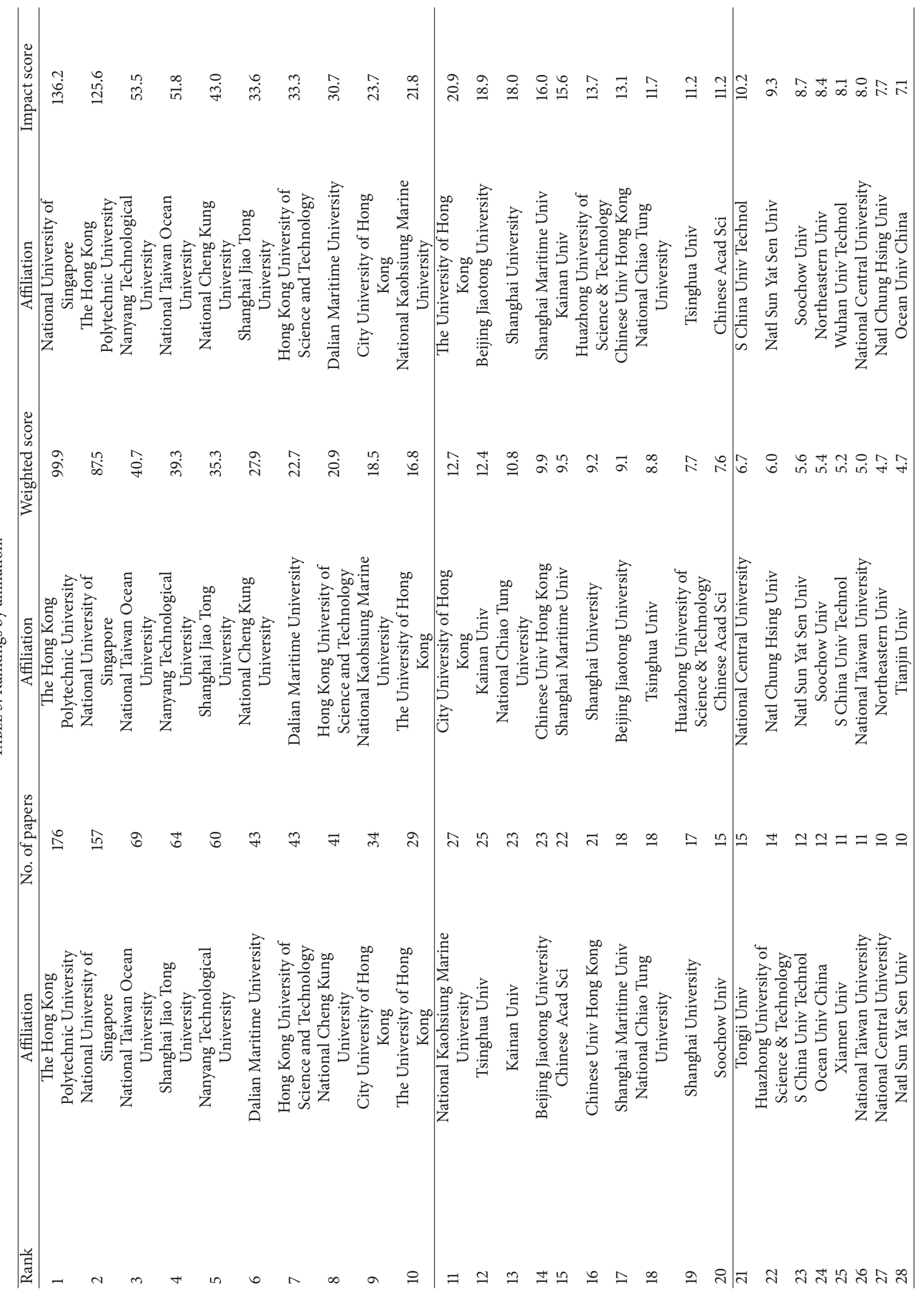




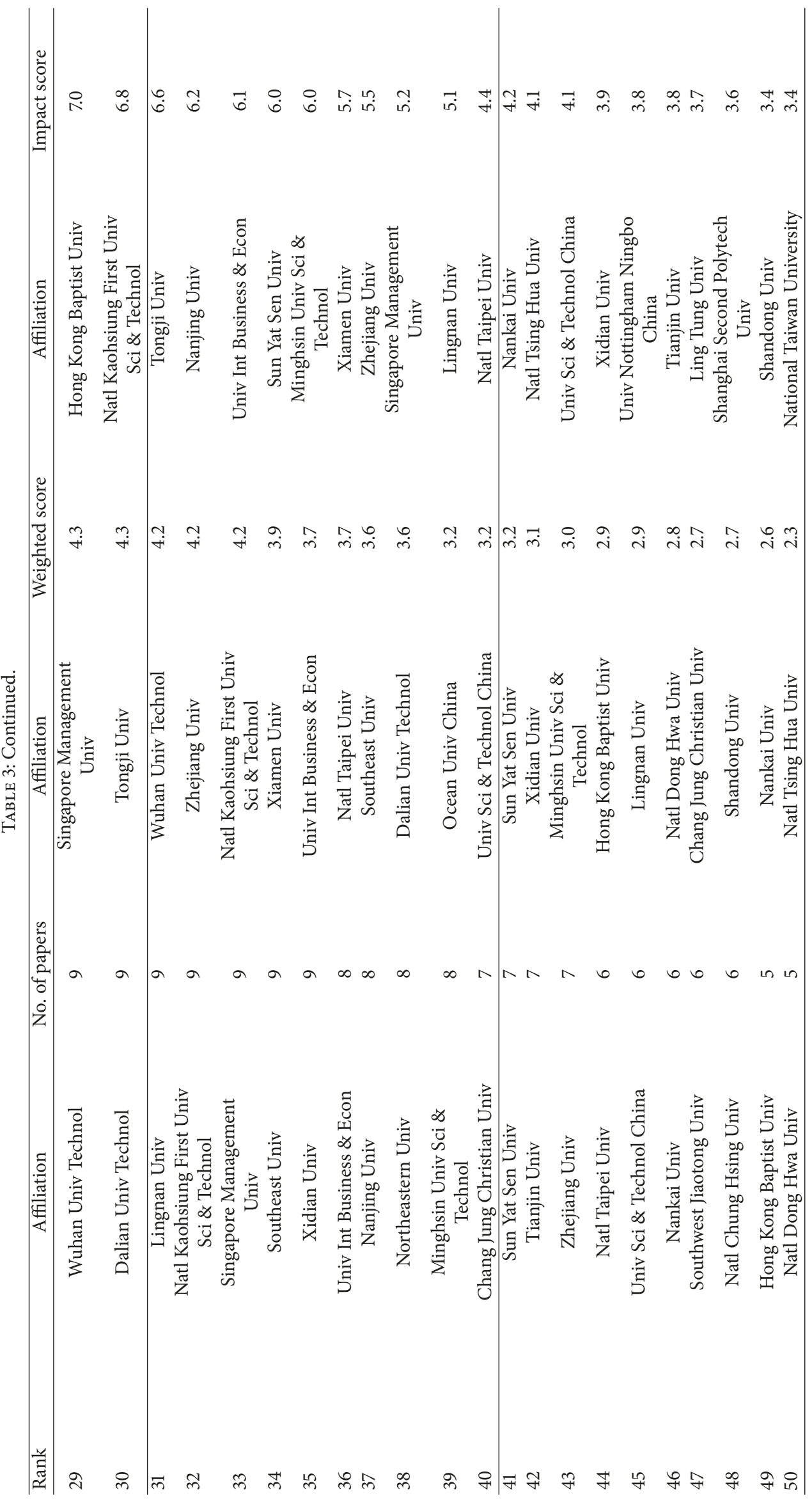




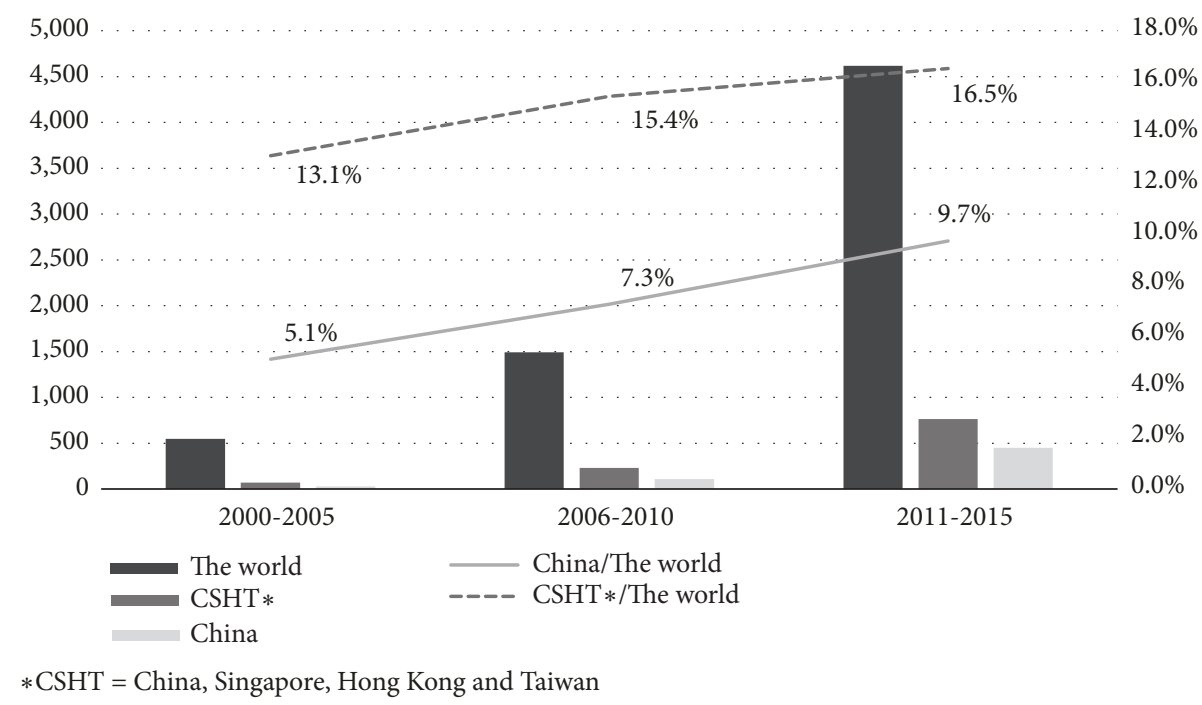

FIgURE 3: Contribution of Countries to Maritime Academia.

TABLE 4: Two-way ANOVA analysis estimates.

\begin{tabular}{lcccc}
\hline & df & Sum sq & F-value & P-value \\
\hline Country & 3 & 186.0 & 10.514 & $<0.000 * * *$ \\
Major & 4 & 217.0 & 9.199 & $<0.000 * * *$ \\
Country * Major & 8 & 217.0 & 4.615 & $0.001 * *$ \\
Residuals & 29 & 165.1 & & \\
Bonferroni p & \multicolumn{5}{c}{$<0.000 * * *$} \\
\hline
\end{tabular}

Significance codes: 0 “***” 0.001 “**” 0.01 “*” 0.05 “.” 0.1 “” 1

increased from $5.1 \%$ to $9.7 \%$ over the same period. Analyzing the methodologies employed in the research, we find that researchers in China preferred optimization to other methods through the entire period. Compared with the methodology by world total using the classification by Talley [19], Chinese researchers relied more upon quantitative approaches such as optimization and proposition. This indicates that Chinese researchers and their affiliations are more likely to perform much better in the future due to the rapidly increasing share of their papers in the world and their strong grounding in the quantitative approach. Moreover, it is important to note that both central and local governments in China have attempted to bring world renowned scholars into their institutions to expedite their quest for world class universities [1]. In this respect, it will be interesting to see how institutions in mainland China, armed with eminent foreign scholars, compete with each other and also the rest of the world.

\section{Conclusion}

This paper examined the top 50 authors and affiliations in China in the field of maritime transportation in comparison with their world ranking. Major findings can be summarized as follows: First, HKPU and NUS are the two leading universities, not only in the Chinese league, but also in the world league. Second, as for the top ten institutions in China, four institutions from Hong Kong join this tier, namely: HKPU, Hong Kong University of Science and Technology, City University of Hong Kong, and the University of Hong Kong. Two universities join the league from each of the remaining economies: NUS and NTU from Singapore; NTOU and National Cheng Kung University from Chinese Taipei; and SJTU and Dalian Maritime University (DMU) from mainland China. Third, four universities from mainland China are listed in the world rankings, namely: SJTU, DMU, BJU, and Shanghai University. Of these, SJTU is the most productive, ranking $12^{\text {th }}$ in the number of papers, $13^{\text {th }}$ in author-weight score, and $21^{\text {st }}$ in impact score. DMU follows, ranking $19^{\text {th }}, 21^{\text {st }}$, and $24^{\text {th }}$ across the same parameters. BJU and Shanghai University show up only in impact score rankings at the $45^{\text {th }}$ and $48^{\text {th }}$ positions, respectively. Though SJTU and DMU are nearly listed in the top 20 category, their rankings in considering the importance of journal by impact factor score drop them into the top 30 tier. Fourth, among the universities originally selected for Project 985, all of whom received billions of dollars, only SJTU is listed in the world ranking. Fifth, star authors are deemed to have contributed greatly to boosting their affiliation rankings when examining chronological dynamic changes of author and affiliation rankings. Sixth, the future of China's rankings is bright in view of their increasing proportion of papers in the world and their strong basis in quantitative methodologies. The policy of hiring eminent foreign scholars in China is also expected to catalyze Chinese institutions to greater competitiveness in the near future.

\section{Appendix}

See Table 5.

\section{Data Availability}

The data used to support the findings of this study are available from the corresponding author upon request. 
TABLE 5: 65 journals selected.

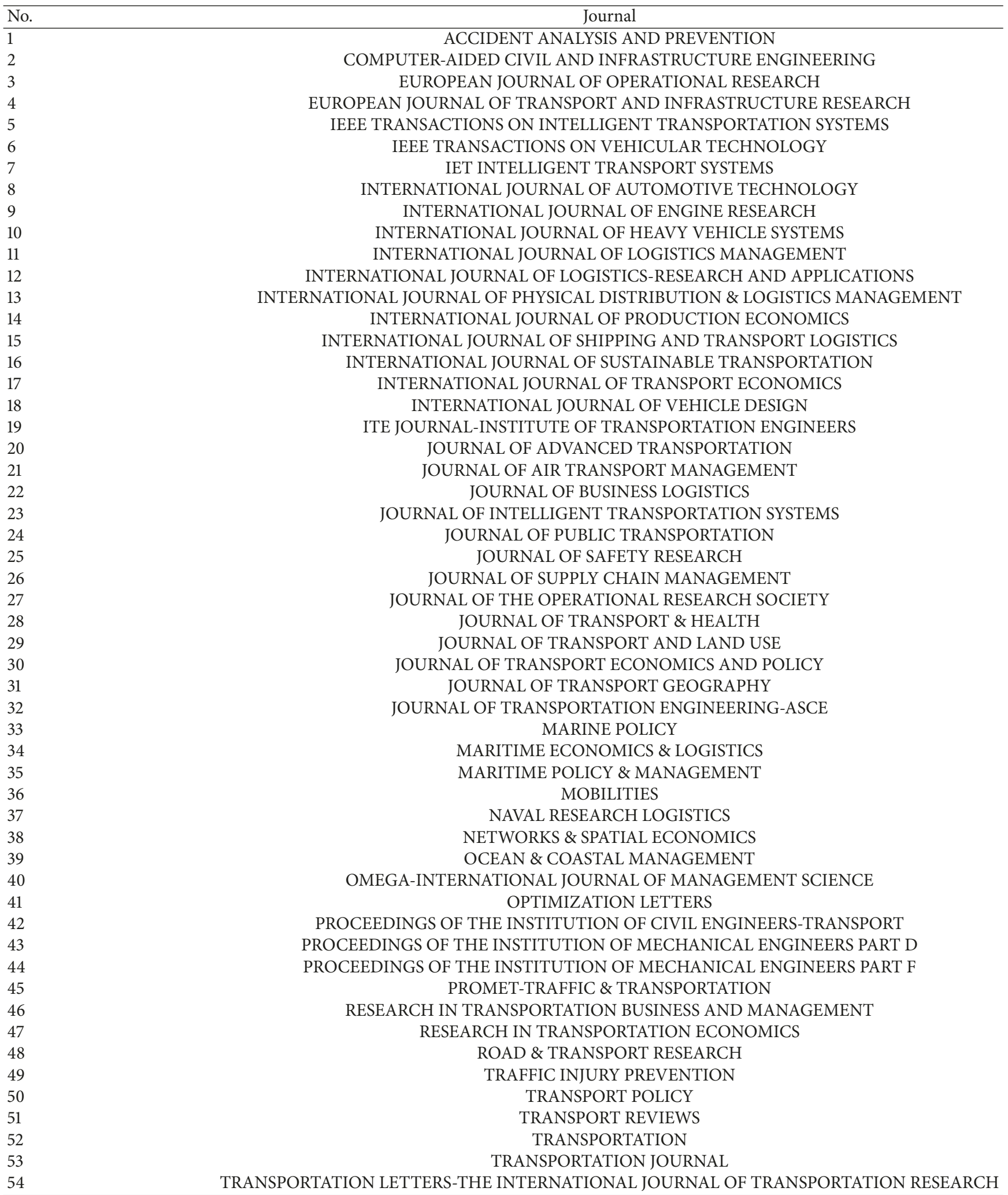


TABLE 5: Continued.

\begin{tabular}{lc}
\hline No. & Journal \\
\hline 55 & TRANSPORTATION PLANNING AND TECHNOLOGY \\
56 & TRANSPORTATION QUARTERLY \\
57 & TRANSPORTATION RESEARCH PART A-POLICY AND PRACTICE \\
58 & TRANSPORTATION RESEARCH PART B-METHODOLOGICAL \\
59 & TRANSPORTATION RESEARCH PART C-EMERGING TECHNOLOGIES \\
60 & TRANSPORTATION RESEARCH PART D-TRANSPORT AND ENVIRONMENT \\
61 & TRANSPORTATION RESEARCH PART E-LOGISTICS AND TRANSPORTATION REVIEW \\
62 & TRANSPORTATION RESEARCH PART F-TRAFFIC PSYCHOLOGY AND BEHAVIOUR \\
63 & TRANSPORTATION RESEARCH RECORD \\
65 & TRANSPORTATION SCIENCE \\
\hline
\end{tabular}

\section{Conflicts of Interest}

The authors declare that they have no conflicts of interest.

\section{References}

[1] K. Ngok and W. Guo, "The quest for world class universities in China: critical reflections," Policy Futures in Education, vol. 6, no. 5, pp. 545-557, 2008.

[2] B. J. Allen and D. B. Vellenga, "Affiliation of authors in transportation and logistics academic journals - an update," Transportation Journal, vol. 26, no. 3, pp. 39-47, 1987.

[3] C. R. Carter, D. B. Vellenga, B. J. Allen, and J. J. Gentry, "Affiliation of authors in transportation and logistics academic journals - another look," Transportation Journal, vol. 41, no. 2-3, pp. 83-93, 2001.

[4] C. R. Carter, D. B. Vellenga, J. J. Gentry, and B. J. Allen, "Affiliation of authors in transportation and logistics academic journals: A reassessment," Transportation Journal, vol. 44, no. 2, pp. 54-64, 2005.

[5] J. J. Gentry, B. J. Allen, and D. B. Vellenga, "Affiliation of authors in transportation and logistics academic journals - revisited," Transportation Journal, vol. 34, no. 3, pp. 54-62, 1995.

[6] S.-H. Woo, S. J. Pettit, D.-W. Kwak, and A. K. C. Beresford, "Seaport research: A structured literature review on methodological issues since the 1980s," Transportation Research Part A: Policy and Practice, vol. 45, no. 7, pp. 667-685, 2011.

[7] S. Woo, S. Pettit, A. Beresford, and D. Kwak, "Seaport research: a decadal analysis of trends and themes since the 1980s," Transport Reviews, vol. 32, no. 3, pp. 351-377, 2012.

[8] P. T. Lee, Y. S. Chung, and J. S. Lam, “Transportation research trends in environmental issues: a literature review of methodology and key subjects," International Journal of Shipping and Transport Logistics, vol. 8, no. 6, pp. 612-631, 2016.

[9] H. Davarzani, B. Fahimnia, M. Bell, and J. Sarkis, "Greening ports and maritime logistics: A review," Transportation Research Part D: Transport and Environment, vol. 48, pp. 473-487, 2015.

[10] Y. T. Chang, K. S. Choi, A. Jo, and H. Park, “Top 50 authors, affiliations, and countries in maritime research," International Journal of Shipping and Transport Logistics, vol. 10, no. 1, pp. 87111, 2018.
[11] W. Shi and K. X. Li, "Themes and tools of maritime transport research during 2000-2014," Maritime Policy \& Management, vol. 44, no. 2, pp. 151-169, 2017.

[12] C. G. Soares, Y. Garbatov, S. Sutulo, and T. A. Santos, Eds., Maritime Engineering and Technology, CRC Press, Taylor\& Francis Group, London, UK, 2012.

[13] C. Hoeffel, "Journal impact factors," Allergy, vol. 53, no. 12, pp. 1225-1225, 1998.

[14] D. C. Greenwood, "Reliability of journal impact factor rankings," BMC Medical Research Methodology, vol. 7, no. 1, article no. $48,2007$.

[15] M. F. Gorman and J. J. Kanet, "Evaluating operations management-related journals via the author affiliation index," Manufacturing and Service Operations Management, vol. 7, no. 1, pp. 3-19, 2005.

[16] M. F. Gorman and J. J. Kanet, "Note-“OM forum: Evaluating operations management-related journals via the author affiliation Index" - Do professors at top U.S. business schools do what they say?" Manufacturing and Service Operations Management, vol. 9, no. 1, pp. 51-53, 2007.

[17] J. P. Man, J. G. Weinkauf, M. Tsang, and J. H. Sin, "Why do some countries publish more than others? an international comparison of research funding, english proficiency and publication output in highly ranked general medical journals," European Journal of Epidemiology, vol. 19, no. 8, pp. 811-817, 2003.

[18] Educational Testing Service, TOEFL Test and Score Data Summary: 2016 Test Year Data, Educational Testing Service, Princeton, NJ, USA, 2017.

[19] W. K. Talley, "Maritime transportation research: Topics and methodologies," Maritime Policy \& Management, vol. 40, no. 7, pp. 709-725, 2013. 


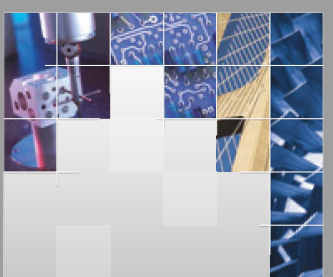

\section{Enfincering}
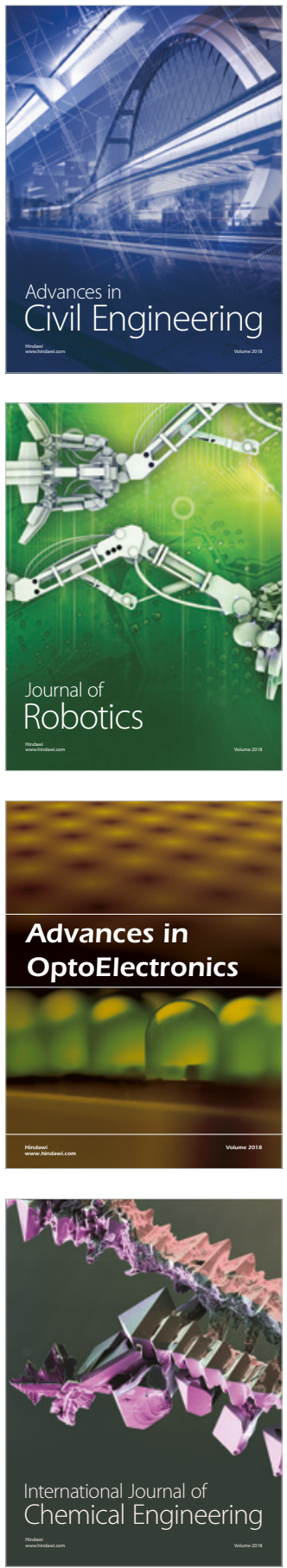

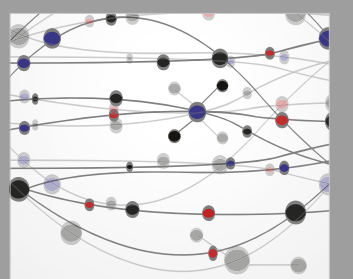

\section{Rotating \\ Machinery}

The Scientific World Journal

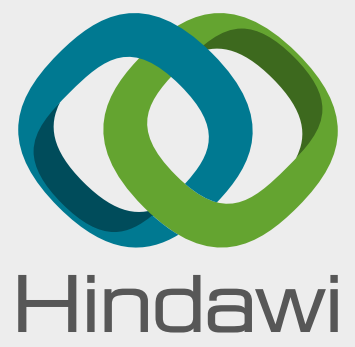

Submit your manuscripts at

www.hindawi.com
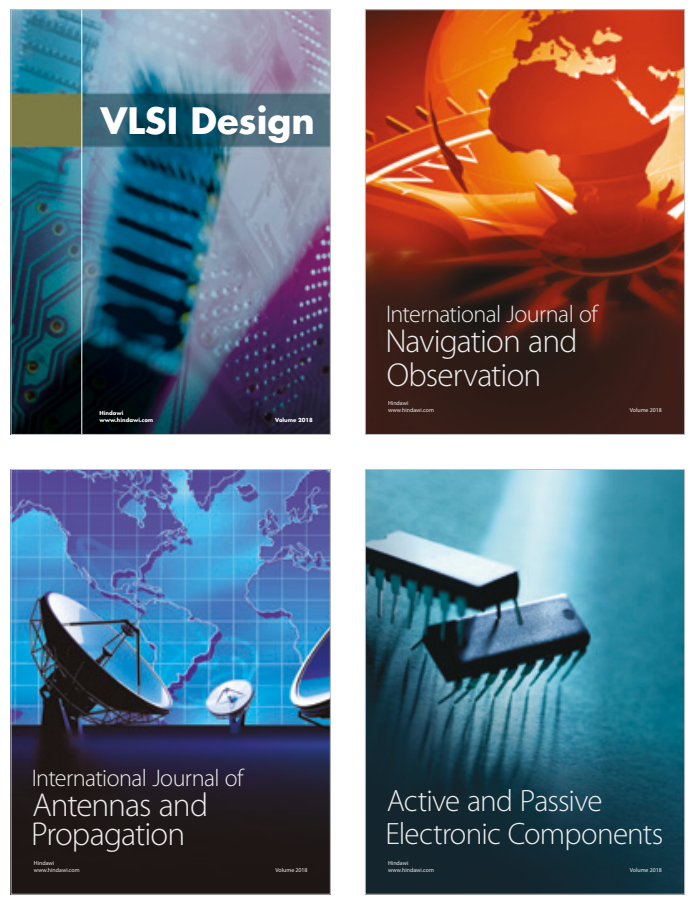
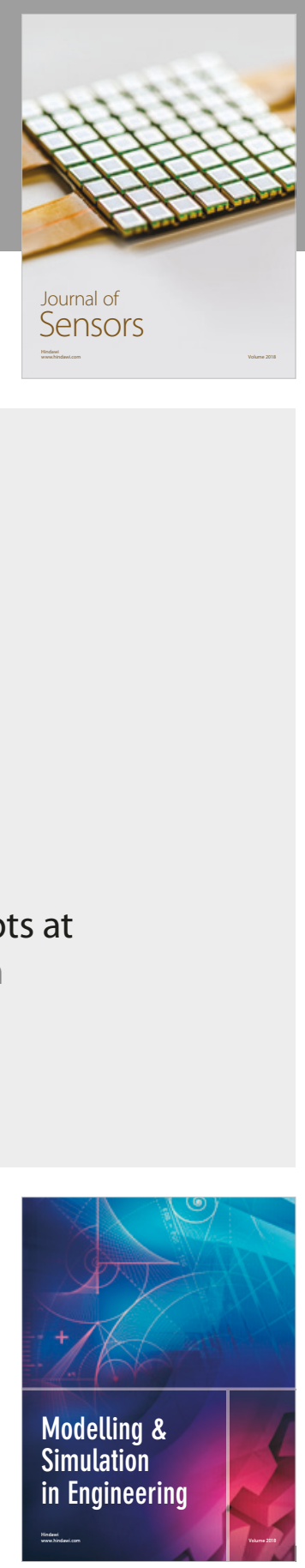

\section{Advances \\ Multimedia}
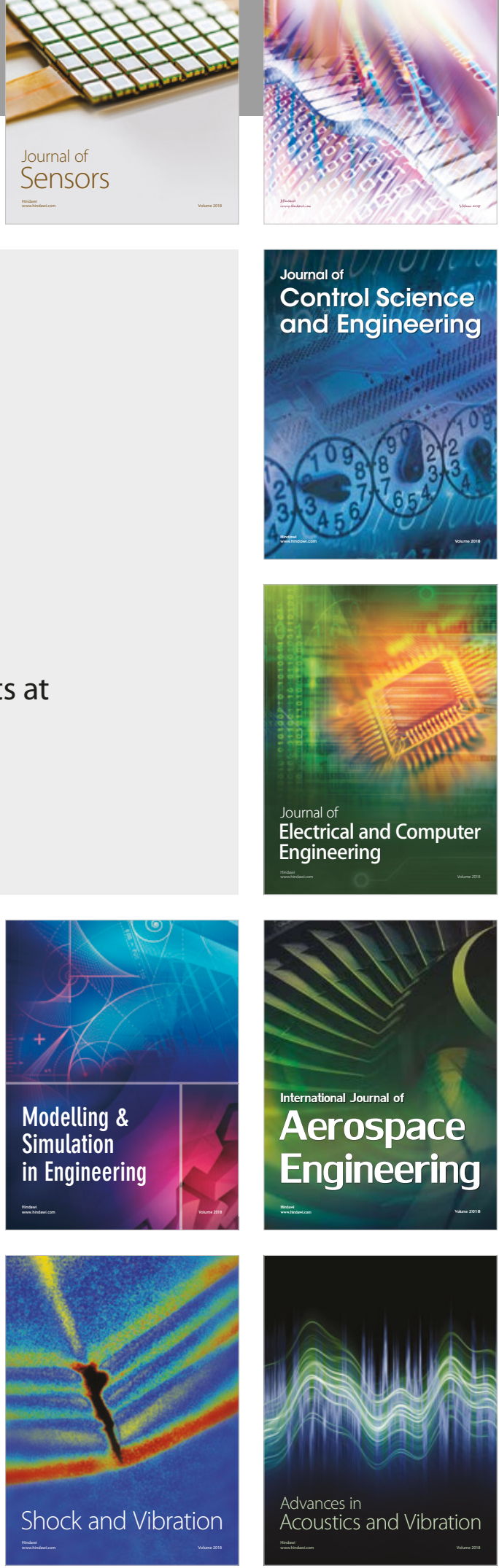